Author's reply: We greatly appreciate Professor and Dr Holland's generous comments on our study and would hasten to reassure them that being unorthodox was never our intention. In our paper the relationship between sudden death and prior psychiatric contact is expressed both as a relative risk and as a standard mortality ratio with results further analysed by diagnostic grouping. The design of this study involved starting with a register of all those reported to the coroner as sudden death and then tracing their prior psychiatric histories. It may well have been more credible to have started from the psychiatric case register and to have traced rates of sudden death in patient cohorts, but that was not the methodology employed. We are in the process, however, of analysing just such a study focusing on a large cohort of patients who have been treated for schizophrenia, and we hope to present this for publication in the near future. This forthcoming paper will, we hope, better address the quite proper concerns raised by these correspondents.

P. E. Mullen Monash University and Victorian Institute of Forensic Mental Health, Department of Psychological Medicine, PO Box 266, Rosanna, Victoria 3084, Australia

\section{Analysis of drop-out data in treatment trials}

Sir: Wearden et al (1998) report the results from a randomised, double-blind, placebocontrolled treatment trial of fluoxetine and graded exercise for chronic fatigue syndrome. In the statistical analysis of their data they use last observation carried forward (LOCF) to replace values missing because subjects dropped-out of the study, and use change scores to estimate treatment effects. Similar analyses are to be found in many other recent papers in the Journal, although it is now well-known that both are poor compared with alternatives. LOCF involves highly unlikely assumptions, for example, that the (unobserved) post-dropout responses remain frozen at their last observed value, and change score estimators have greater variance than estimators based on analysis of covariance - consequently using change scores is less powerful. Full explanations are available in Frisson \& Pocock (1992), Everitt $(1995,1998)$ and, in particular, chapter 7 of Senn (1997).

Everitt, B. S. (1995) The analysis of repeated measures: a practical review with examples. Stotisticion, 44. $113-135$.

- (1990) Analysis of longitudinal data: Beyond MANOVA. British journal of Psychiatry, I72, 7-10.
Frisson, L. \& Pocock, S. J. (1992) Repeated measures in clinical trials: analysis using mean summary statistics and its implication for design. Stotistics in Medicine, II. 1685-1704.

Senn, S. (1997) Statistical Issues in Drug Development. Chichester: Wiley.

Wearden, A. J., Morrias, R. K., Mullis, R., et al (1998) Randomised double-blind, placebo-controlled trial of fluoxetine and graded exercise for chronic fatigue syndrome. British journal of Psychiatry, I72, 485-490.

B. S. Everitt Department of Biostatistics and Computing, Institute of Psychiatry, De Crespigny Park, Denmark Hill, London SE5 8AF

\section{Validity of the Chinese version of the Edinburgh Postnatal Depression Scale}

Sir: Lee et al (1998) purport to demonstrate the validity of the Edinburgh Postnatal Depression Scale (EPDS) in a population of Chinese women. We would interpret the study as demonstrating the very poor properties of the EPDS - at least in this Chinese version.

If we assume that major depression criteria are taken as the 'gold standard' against which the EPDS is being validated, that the point prevalence of major depression is approximately $5 \%$ and, for a cut-off value of $9 / 10$, that the sensitivity is $82 \%$ and the specificity $86 \%$, then if 1000 women are screened for major depression, then 174 cases would be identified but of these, 133 would be false positives. It would be tendentious to assert that an instrument has good operating properties if it is wrong three times more often than it is right.

The problem, which is a generic one with screening tools, is that when the base rate of the phenomenon in question is low, the specificity of the tool must be very high in order to avoid the number of false positives outweighing the number of true positives. Lee et al's paper demonstrates exactly this point. Contrary to the authors' conclusions, their data indicate the poor utility of the EPDS for population screening and this is clearly of some concern given that the scale is commonly used for this purpose in clinical practice.

Lee, D. T. S., Yip, S. K., Chiu, H. F. K., et al (1990) Detecting postnatal depression in Chinese women. Validation of the Chinese version of the Edinburgh Postnatal Depression Scale. British Journal of Psychiatry. I72, 433-437.

\section{Hawley, T. Gale Hertfordshire}

Neurosciences Research Group, East Hertfordshire NHS Trust, Mental Health Unit, QEIl Hospital, Howlands, Welwyn Garden City, Herts AL7 4HL
Author's reply: Drs Hawley and Gale base their calculation on the assumption that major depression is the gold standard against which the EPDS is being validated. This assumption, however, is untrue.

The EPDS is designed to screen for both major and minor depression in recently delivered women. In the original validation study by Cox (1987), as well as in subsequent validations in other cultures, the EPDS was validated using major depression plus minor depression as the gold standard criterion. We followed the same methodology in our study.

The point prevalence of major depression plus minor depression in our study subjects is approximately $12 \%$. If the calculation of psychometric properties is based on this prevalence, the positive predictive value will be $44 \%$, as we reported. A calculation based on $5 \%$ prevalence will underestimate the positive predictive value of the rating scale.

Cox, J. L., Holden, J. M. \& Sagovaky, R. (1987) Detection of postnatal depression. Development of the 10-item Edinburgh Postnatal Depression Scale. British Journal of Psychiotry. 150, 782-786.

D.T. S. Lee Department of Psychiatry, The Chinese University of Hong Kong, Shatin NT, Hong Kong

\section{Compliance, adherence, concordance ... .}

Sir: Contributors to the Jourmal (Healey et al, 1998; Kemp et al, 1998) are still using the term 'compliance'. Psychiatrists, of all specialities, should move away from the attitude that patients should be compliant (i.e. submissive, yielding, acquiescent, obedient). The time has come to recognise that compliance is an outdated concept. Contributors to the British Medical Journal (e.g. Lewin, et al, 1998) have recently used the term 'adherence' (state of adhering, steady attachment).

Furthermore, the term 'non-compliance' indicates that either the patient is completely compliant or the opposite. However, adherence is better conceptualised along a continuum, with the poles being $100 \%$ adherence (extremely rare) and no adherence (extremely rare), with a majority falling somewhere in between.

Healey, A., Knapp, M., Astin, J., et ol (1998) Cost-effectiveness evaluation of compliance therapy for people with psychosis. British journal of Psychiatry. I72. 420-424. 
Kemp, R., Kinov, G., Everitt, B., $x$ of (1998) Randomised controlled trial of compliance therapy. 18-month follow-up. British journal of Psychiotry, I72. $413-419$.

Lewin, R., Indeton, R., Newens, A., et of (1990) Adherence to cardiac rehabilitation guidelines: a survey of rehabilitation programmes in the United Kingdom. British Medical Journal, 316, 1354.

B. Lask Great Ormond Street Hospital for Children NHS Trust, Department of Psychological Medicine, Great Ormond Street, London WCIN 3JH

Author's reply: There has been much discussion over the terminology of treatment compliance in recent decades (Kemp \& David, 1997; McEvoy, 1998). I am not wedded to any particular term. Anyone who takes an interest in compliance therapy will see that the principles are based on the search for mutual understanding and collaboration between doctor (or therapist) and patient (or client or user). I agree that as psychiatrists we should be especially alert to such matters but we should also acknowledge that we alone are able to enforce treatment in circumstances where consensus is not possible but treatment essential. For some cases, over $50 \%$ of patients in the Kemp et al (1998) study, enforced compliance may be the first step towards adherence and later concordance (Kane et al, 1983; Kjellin et al, 1997).

Kane, J. M., Quittin, F., Rifkin, A., ex of (1983) Attitudinal changes of involuntarily committed patients following treatment. Archives of General Psychiatry, 40. 374-377.

Kemp, R. \& David, A. (I997) Insight and compliance. In Treatment Compliance and the Treatment Alliance in Serious Mental Iliness (ed. B. Blackwell), pp. 61-84. The Netherlands: Harwood Academic.

_, Kirov, G., Everitt, B. (IS98) Randomised controlled trial of compliance therapy. 18-month followup. British journal of Psychiotry, 172, 413-419.

Kjellin, L., Anderseon, K., Candefjord, I. L., et of (1997) Ethical benefits and costs of coercion in shortterm inpatient psychiatric care. Psychiatric Services, 48. 1567-1570.

McEvo\% J. P. (1990) The relationship between insight in psychosis and compliance with medications. In Insight and Psychosis (eds X. F. Amador \& A. S. David). New York: Oxford University Press.

A. S. David Department of Psychological Medicine, Institute of Psychiatry, De Crespigny Park, Denmark Hill, London SE5 8AF

\section{One hundred years ago}

\section{Wandering lunatics}

The city coroner of Liverpool, Mr. Sampson, has lately drawn attention to the fact that there is no suitable provision for dealing with persons suffering from the milder forms of mental aberration, and who, while they show no definite marks of insanity, are unable to give any satisfactory account of themselves, and are clearly in a condition in which insane impulses might at any time arise with grave danger either to themselves or to others. Such persons are frequently found by the police wandering at large, and are then conveyed to the bridewell and examined by a medical man. If they are found to be unable to take care of themselves, and yet the medical man does not feel justified in certifying then and there that they are insane, it is manifest that, in the interests both of the sufferers themselves and of the public, they should be retained in some suitable place until the cause and nature of the mental aberration can be ascertained. Until recently no serious difficulty in dealing with such cases has arisen, since they have been received into the workhouse on a doctor's note, and there dealt with as the occasion demanded. Latterly, however, the authorities of Mill Road Infirmary have declined to receive them, owing, it is stated, to there being no accommodation in the workhouse for the alleged lunatics; and there has been no alternative but to take them back to the bridewell, where there is no proper provision for attending to them, and to bring them before the presiding magistrate the following day. As these persons are not charged with any offence for which they can be committed to goal [sic], there is no alternative but to discharge them.

It is high time that reception houses for all cases of supposed insanity were established in the great centres of population. The Barony Parish of Glasgow has set apart observation wards in the ordinary poorhouse to meet this difficulty, and we understand that good results have been obtained there, not only for the individuals, but also for the ratepayers.

\section{REFERENCE}

journal of Mental Science, April 1898, 449-450.

Researched by Henry Rollin, Emeritus Consultant Psychiatrist. Horton Hospital, Epsom, Surrey

\section{Corrigenda}

Harris, E. C. \& Barraclough, B., BJP, 173, 11-53. The third sentence of the fifth paragraph under the subheading "Opioid dependence and abuse (DSM-III-R 304.00 and 305.50) (Tables 5a-e)" (p.19, third column) should read: "The all cause SMR for HIV+ abusers was sixty times the expected compared with 17 times the expected for HIV - abusers." Table $4 b$
(Alcohol dependence and abuse: males, p. 15): genito-urinary SMR of 169 should not have an asterisk (i.e. the figure is nonsignificant). Table 35a (Psychiatric illness, all treatments: both genders, p. 42): infectious SMR of 203 should not have an asterisk (i.e. the figure is non-significant).

Londborg, P. D., Wolkow, R., Smith, W. T., et al, BJP, 173, 54-60. The endpoint values on Fig. 1 (p. 57) and Fig. 2 (p. 58) were omitted. In Fig. 1 (mean weekly frequency of panic attacks by group, expressed as a per cent of frequency at baseline) the endpoint values are: placebo 0.61 , pooled sertraline 0.35 . In Fig. 2 (percentage time spent in anticipatory anxiety per week) the endpoint values are: placebo 15.2 , pooled sertraline 10.8 . 